\title{
International Comparison Analysis on Fire Risk Among the United States, The United Kingdom, and Japan
}

\author{
AI SEKIZAWA \\ Fire Research Institute \\ 3-14 Nakahara, Mitaka, Tokyo 181, Japan
}

\begin{abstract}
Through comparison analyses based on fire statistics of the U.S.A., the U.K., and Japan, characteristics of fire risk of these countries were examined especially from the viewpoint of life loss risk. It was found that each country has its own unique fire problems in some particular aspects, although there is also considerable similarity among these countries. Also, discussed was what causes the differences among fire death rates and fire death patterns for particular age groups among the countries. This paper concludes that further study on the basis of international collaboration is needed to make the answers to these questions more clear in detail.
\end{abstract}

KEYWORDS : International Comparison, Fire Statistics, Fire Death, Fire Risk.

\section{INTRODUCTION}

As Japan is facing the problem of a rapidly aging society, we need to learn the experiences of other developed countries from the viewpoint of mitigation of potential life loss caused by accidental fires, especially for our increasing population of aged or disabled people. Through international comparison analyses on fire risk by condition and/or age of people etc., based on fire statistics and other relating statistical data, we can learn and discuss what causes the differences of fire risk among the countries, and we can also examine which features are important and/or instructive for the promotion of fire protection measures for high risk target groups in each country.

\section{SOURCES FOR FIRE STATISTICS}

The Home Office of the U.K. publishes annually a report of national fire statistics entitled "Fire Statistics - United Kingdom" [1], which is the source of all U.K.'s fire statistics used 
here. The Fire Defense Agency in Japan publishes annually the "White Book on Fire Service" [2] which includes many fire statistics. However, the main sources for fire statistics on Japan is the data base of fire incidents and fire deaths of the Fire Defense Agency. For U.S.A. fire statistics, publications of the NFPA such as "The U.S. Fire Problem Overview Report through 1990" [3] and "Patterns of Fire Casualties in Home Fires by Age and Sex, 1985-89" [4] are the main sources. Special analysis of the NFPA's fire data base by Dr. John Hall is also used here.

\section{RESULTS AND DISCUSSION}

\section{Overview of Fire Loss among the U.S.A., the U.K., and JAPAN}

Table 1 shows the number of reported fires and fire deaths, and their rates per population, among countries including the U.S.A., the U.K., and Japan. The fire incident rates relative to population of the U.S.A. and the U.K. are much higher than Japan's in 1989. However, differences in fire incident rates per population depend greatly on differences in definitions or reporting systems for fire incidents, especially in small fires, so they do not seem to reflect real differences in fire incidence.

By contrast, the number of reported fire deaths seems to be more reliable because there is not so much change in the reporting system for fire deaths among countries. In fact, fire death rates per million people are relatively in good order in the countries in Table 1. The U.K. and Japan have almost the same values, and the U.S.A. has a rate roughly $40 \%$ to $50 \%$ higher than these two countries.

Figure 1 shows ratios of structure fires by property use in the U.S.A., the U.K. and Japan respectively. The percentage of residential fires in each country is more than $50 \%$, especially high in the U.S.A. (72.1\%). The U.S.A. has a relatively lower percentage of industrial fires than the U.K. and Japan. However, there is not a considerable gap in other minor categories of property use. As for civilian deaths from structure fires by property use, the share for residential fire deaths is overwhelming and almost the same in these countries. Based on the average during 1985-1989, the share for residential fire deaths of the U.S.A. is $94.6 \%$, followed by Japan's $89.4 \%$ and the U.K.'s $89.3 \%$.

TABLE 1. Comparison of fire loss among countries in 1989 [1].

\begin{tabular}{l|r|r|r|r}
\hline Country & \multicolumn{1}{|c|}{$\begin{array}{c}\text { Number of } \\
\text { fires }\end{array}$} & $\begin{array}{c}\text { Fires per 10,000 } \\
\text { people }\end{array}$ & $\begin{array}{c}\text { Number of fire } \\
\text { deaths }\end{array}$ & $\begin{array}{c}\text { Fire deaths per } \\
\text { million people }\end{array}$ \\
\hline Japan & 55,763 & 4.6 & 1,747 & 14.3 \\
U.S.A. & $2,115,000$ & 85.2 & 5,410 & 21.8 \\
U.K. & 456,179 & 79.7 & 901 & 15.7 \\
Korea & 12,704 & 3.0 & 447 & 10.5 \\
Norway & 13,084 & 30.9 & 72 & 17.0 \\
Canada & 67,182 & 25.6 & 500 & 19.1 \\
New Zealand & 19,004 & 56.8 & 47 & 14.1 \\
\hline
\end{tabular}


Figure 2 shows the share for major causes of residential fires in the U.S.A., the U.K., and Japan. Among these countries, a considerable gap is found in the causes of "Cooking", "Heaters", and "Electric" which stands for electrical appliances and distribution system. As for "Cooking", the U.S.A. $(21.3 \%)$ has a relatively smaller share than the U.K. $(39.6 \%)$ and Japan $(31.1 \%)$. The U.S.A.'s share of cooking fires is quite large, but it is not the largest among the U.S.A.'s causes, while the share for cooking fires in Japan or the U.K. is the largest. As for "Heaters", the U.S.A. has a much lager share than Japan and the U.K. As for "Electric", the U.S.A. and the U.K. have almost the same share, while Japan has nearly $40 \%$ of that share. Figure 3 shows major causes of fatal fires in residences. As compared with the gap among the countries seen in Figure 2, there is not so much of a gap in both the proportion and the order of major causes of residential fatal fires except for Japan's share of "Heaters". As a result of comparison of major causes of residential fatal fires, it seems that the U.S.A., the U.K., and Japan have common fire death patterns and problems.

\section{Trend in Fire Death Rates}

Figure 4 shows the trend in fire death rates per million people in the U.S.A., the U.K., and Japan during 1975 through 1989. Japan and the U.K. have had quite similar and stable values for this period. By contrast, U.S.A. fire death rates have drastically declined for the same period, although the rates were much higher than the rates for the other two countries. During 1976-1978, U.S.A. fire death rates were more than twice the rates in the U.K. and Japan, but during 1984-1989, the rates became roughly 50\% higher.

For the reason of this remarkable fire death reduction, the growth in popularity of smoke detectors in U.S.A. homes is often cited, but the author still would like to emphasize the need for further study because the U.K. has been just following the U.S.A. in popularization of smoke detectors in recent years. If incendiary suicide, which is Japan's unique problem, is excluded, Japan's fire death rate has slightly declined for this period and was roughly $40 \%$ lower than the rates in the U.K. during 1984-1989.

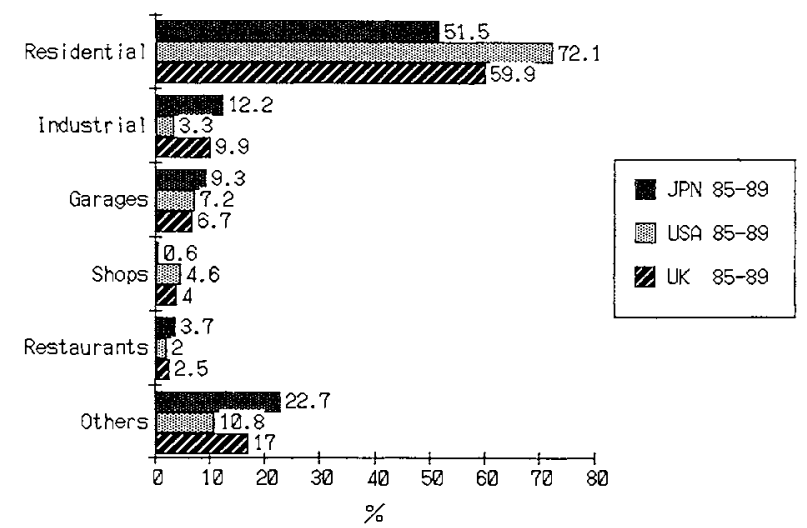

FIG. 1 Structure fires by property use 


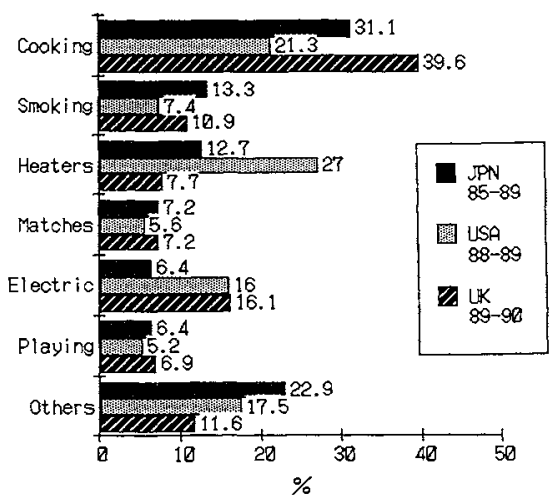

FIG. 2 Major causes of residential fires

* Japan's data: Without incendiary fires

* * Unknown causes are allocated over known causes for USA and Japan.

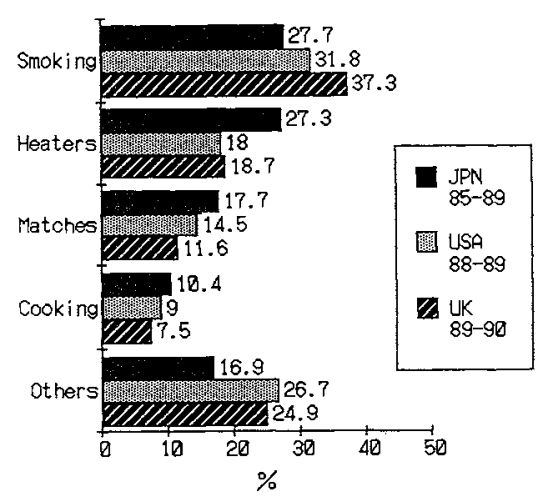

FIG. 3 Major causes of fatal residential fires

* Japan's data: Without incendiary suicides * *Unknown causes are allocated over known causes for USA and Japan.

\section{Fire Death Rate by Age Group}

Figure 5 shows structure fire death rates per million people by age group for the U.S.A. (average of 1988-1989), the U.K. (average of 1989-1990), and Japan (average of 1985-1989 without incendiary suicides ). In the average for all ages, the U.S.A. has the highest fire death rate (20.1), followed by the U.K. (12.5) and then Japan (8.0). However, it is commonly seen for each country that older adults have a much higher fire death rate than overall average and especially in Japan. For example, overall Japan's fire death rate is only $40 \%$ of the corresponding rate in the U.S.A., but the fire death rate for ages 80 and older in Japan is $15 \%$ higher than the counterpart in the U.S.A.

As one reason for this disproportionally high fire death rate of older adults in Japan, it is considered that Japanese older adults are more likely to live in poor conditions such as small

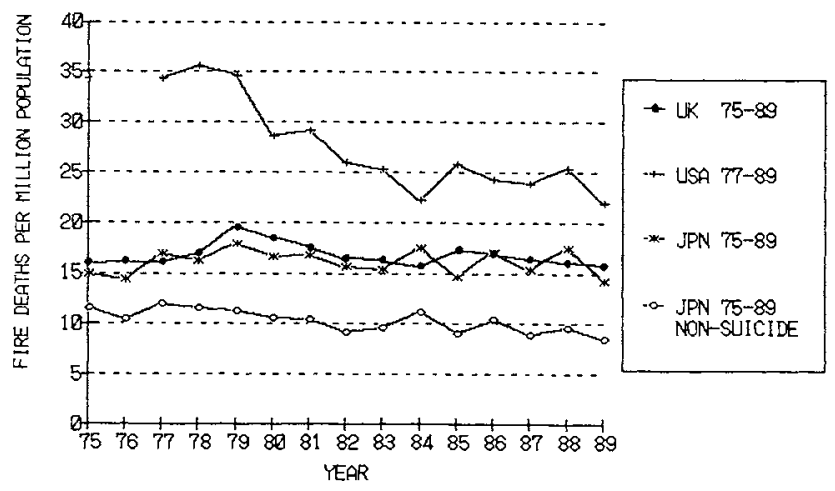

FIG. 4 Trend in fire death rates 
wooden homes or older equipment with less care from society than other developed countries. Younger children (ages 0-4) also have a higher fire death rate than overall average in each country but especially in the U.S.A. The fire death rate of younger children in the U.S.A. is roughly 2.5 times higher than overall average, while the corresponding fire death rate in Japan or the U.K. is only $15 \%$ or $40 \%$ higher than overall average. FAHY, Rita [5] suggested a higher incidence of single-parent families and/or unsupervised children as probable reasons for this difference.

The proportion of residential fire deaths by age group as shown in Figure 6 also shows the differences mentioned above among the countries. Japan's older adult (65-) share of residential fire deaths is almost a half of the total (47.0\%), followed by the U.K.'s $(42.2 \%)$, while the U.S.A. counterpart is only a quarter of the total $(23.8 \%)$. By contrast, the younger children (-4) share in the U.S.A. is about twice the share in both the U.K. and Japan. From the pattern of proportions, the U.K. is more similar to Japan than to the U.S.A.

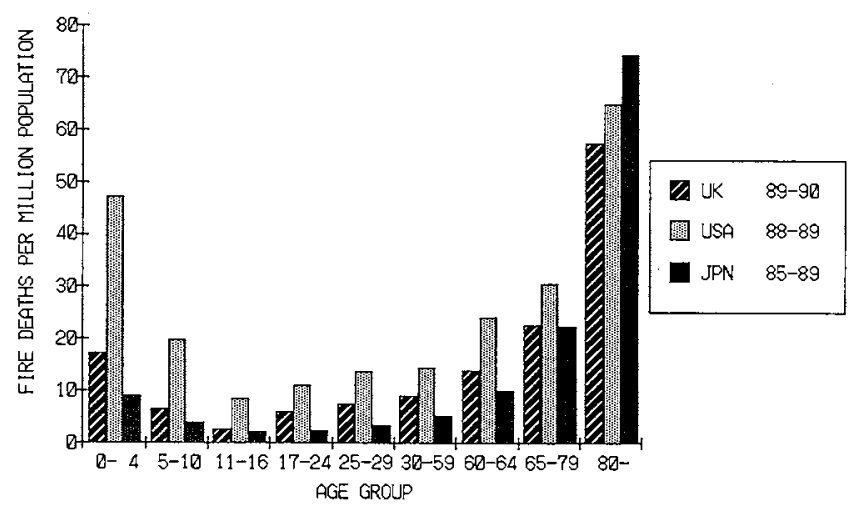

FIG. 5 Structure fire death rates by age group

*Japan's data: Without incendiary suicides

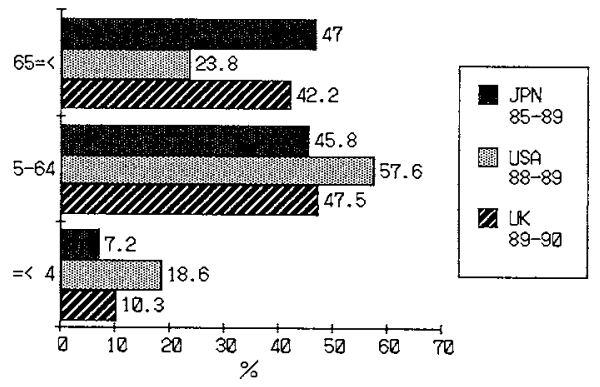

FIG. 6 Proportion of residential fire deaths by age group

*Japan's data: Without incendiary suicides 
Figure 7 shows the proportion by location of victim at time of ignition in each country respectively. One can see clear differences in the pattern of proportion among the countries. $67.4 \%$ of Japan's victims were in the room of fire origin, followed by $55.7 \%$ of the U.K.'s, while U.S.A.'s corresponding proportion is only $39 \%$. By contrast with above, proportions of "on the floor but not in the room of fire origin" and "in the building but not on the floor of fire origin" are in a reverse order among the countries. As roughly $60 \%$ of the U.S.A.'s victims were not in the room of fire origin, the U.S.A. can take more advantage of the availability of early warning by smoke detectors for fire death prevention than other two countries.

However, why is there so much of a gap among the countries in the proportions for locations of victims? One probable reason for higher percentages of victims in the room of fire origin in Japan and the U.K. is higher percentages of older victims in both countries. First, older adults are more likely to be intimately involved with ignition, e.g. causes such as "apparel ignited" and "smoking in bed". Also, if older adults suffer ignition of fire in a room they occupy when they are alone, they are more likely to be victims, due to their less evacuation capability. Figure 8 and Figure 9 are helpful to explain this tendency. Figure 8 shows the proportion by location and physical condition of victims at time of ignition in Japan. The victims who had physical handicap like "Bedridden", "Handicapped", and "Sick" tended to be in the room of fire origin in Japan. And, most of these victims were 65 and older. Figure 9 shows the proportion by location and age of victims in the U.S.A. It is also seen that older victims tended to be closer to the fire origin.

The proportion of estimated reasons for residential fire deaths for each group by physical condition of victims based on the data of fire death reports in Japan is described in Table 2. The information in this Table gives us a more direct explanation for the probable situation of older and disabled victims discussed above. The victims, who were bedridden, disabled physically, and aged, were killed in residential fires mostly by reason of incapability, failure, or delay of evacuation which are related to less capability of evacuation. For these

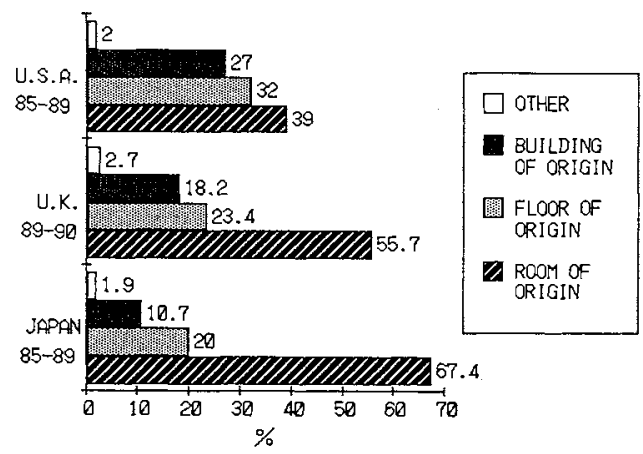

FIG. 7 Location of victims of residential fires at time of ignition * Japan's data: Without incendiary suicides 


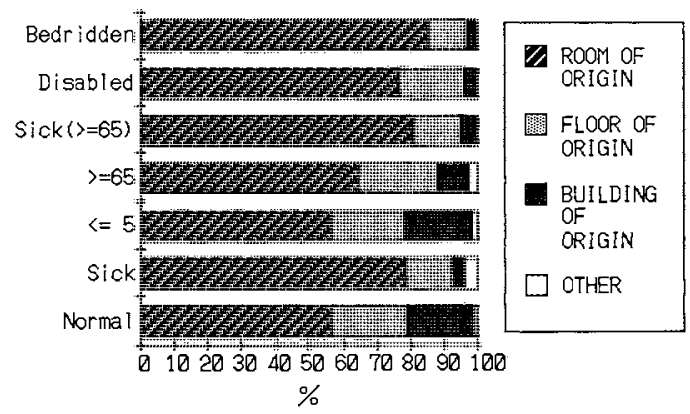

FIG. 8 Location of victims by condition at time of ignition

* Data: Average of 1985-89 for residential fires in Japan without incendiary suicides

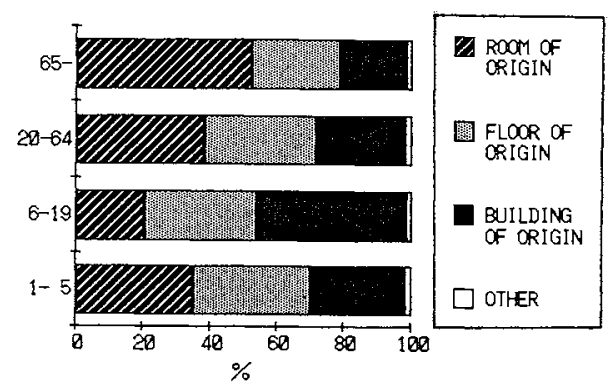

FIG. 9 Location of victims by age group at time of ignition

* Data: Average of $1985-89$ of residential fires in the U.S.A.

TABLE 2. Estimated reasons for residential fires deaths in Japan.

\begin{tabular}{|c|c|c|c|c|c|c|c|}
\hline \multirow{2}{*}{$\begin{array}{l}\text { Physical conditions } \\
\text { of victims }\end{array}$} & \multicolumn{5}{|c|}{ Estimated reasons for residential fire deaths } & \multirow[b]{2}{*}{$\begin{array}{l}\text { Others or } \\
\text { Unknown }\end{array}$} & \multirow[b]{2}{*}{ Total } \\
\hline & $\begin{array}{r}\text { Delay of } \\
\text { detection }\end{array}$ & $\begin{array}{r}\text { Delay of } \\
\text { evacuation }\end{array}$ & $\begin{array}{l}\text { Failure of } \\
\text { evacuation }\end{array}$ & $\begin{array}{l}\text { Incapability of } \\
\text { evacisation }\end{array}$ & $\begin{array}{l}\text { Ignition on } \\
\text { apparel }\end{array}$ & & \\
\hline Bedridden & $14.5 \%$ & $0.7 \%$ & $17.6 \%$ & $55.6 \%$ & $7.8 \%$ & $3.8 \%$ & $100 \%$ \\
\hline Disabled physically & 22.7 & 8.8 & 24.2 & 19.1 & 14.5 & 10.7 & 100 \\
\hline Elderly with sickness $(>=65)$ & 22.4 & 16.4 & 12.6 & 8.7 & 21.3 & 18.6 & 100 \\
\hline Elderly $(>=65)$ & 26.6 & 20.2 & 14.9 & 5.9 & 13.0 & 19.4 & 100 \\
\hline Younger children $(<=5$ ) & 13.1 & 1.4 & 5.5 & 66.3 & 1.4 & 12.3 & 100 \\
\hline Persons with sickness & 31.9 & 8.0 & 5.9 & 13.0 & 6.7 & 34.5 & 100 \\
\hline Normal in condition & 37.9 & 10.9 & 12.5 & 5.6 & 4.1 & 29.0 & 100 \\
\hline
\end{tabular}

* Data: Average of 1985-89 for residential fires in Japan without incendiary suicides. 
victims, a relatively large proportion also appears in the reason of ignition on wearing apparel. By contrast, for the victims who were normal in physical condition or simply sick, the shares in those reasons mentioned above are relatively small and the share in delay of detection instead is higher compared with other groups. Younger children were killed in residential fires mostly by reason of incapability of evacuation which indicates they were unattended by parents at a fire.

Another possible reason for the question above could be the differences in the design and construction of houses among the countries as suggested by HALL, John [6]. U.S.A. homes might have more open layouts than U.K.'s, but it seems that Japan's homes have even more open layouts than U.S.A.'s. Therefore, this reason is still controversial and should be examined in the future.

\section{Condition of Victims by Residential Fires at Ignition by Age Group}

Table 3 shows a comparison between the U.S.A. and Japan on victim condition at ignition by age group. For all age groups, a considerable gap can be found in the victim condition categories of "Asleep" and "Bedridden". Japan has a smaller proportion in "Asleep" and 3.5 times larger proportion in "Bedridden" than the U.S.A. However, for younger children, 5 and under, proportion patterns by victim condition in both countries are quite similar. This means that fire death pattern of younger children is probably common in the U.S.A. and Japan. For age group, 6 to 64 , the gap of proportion of each category between the U.S.A. and Japan is almost same as the gap for all age groups. For age group, 65 and older, the largest proportion of victim condition appears in "Bedridden" (35\%) in Japan, but in "Asleep" (40 \%) in the U.S.A. The proportion of "Bedridden" in the U.S.A. is only $19 \%$. However, if "Bedridden" and "Too old to act" are combined together, U.S.A.'s proportion (31\%) becomes closer to Japan's (37\%). The proportion of "Asleep" $(23 \%)$ in Japan for this age group is about a half of the counterpart in the U.S.A. and even less than the proportion of "Awake and unimpaired" (32\%) among Japan's condition categories.

TABLE 3. Condition of atalities from esidential fires at ignition by age group.

\begin{tabular}{l|cccc|cccc}
\hline \multirow{3}{*}{ Conditions } & \multicolumn{3}{|c|}{ U.S.A. *3 } & \multicolumn{4}{c}{ Japan *4 } \\
\cline { 2 - 9 } & $\begin{array}{l}\text { All age } \\
\text { groups }\end{array}$ & -5 & $6-64$ & $65-$ & $\begin{array}{c}\text { All age } \\
\text { groups }\end{array}$ & -5 & $6-64$ & $65-$ \\
\hline Asleep & $55 \%$ & $53 \%$ & $62 \%$ & $40 \%$ & $31 \%$ & $46 \%$ & $38 \%$ & $23 \%$ \\
Bedridden etc. *1 & 6 & 0 & 3 & 19 & 21 & 3 & 10 & 35 \\
Impaired by alcohol *2 & 9 & 0 & 15 & 6 & 8 & 0 & 15 & 3 \\
Too young to act & 9 & 34 & 1 & 0 & 3 & 37 & 0 & 0 \\
Too old to act & 3 & 0 & 0 & 12 & 1 & 0 & 0 & 2 \\
Awake & 14 & 11 & 14 & 18 & 26 & 9 & 22 & 32 \\
Other & 4 & 2 & 5 & 5 & 10 & 5 & 14 & 6 \\
\hline Total & $100 \%$ & $100 \%$ & $100 \%$ & $100 \%$ & $100 \%$ & $100 \%$ & $100 \%$ & $100 \%$ \\
\hline
\end{tabular}

*1: Including other physical handicap

*2: Including impaired by drugs

*3: Source 1985-89 NFIRS and NFPA survey [5]

*4: Source 1985-89 Fire death data of Fire Defense Agency 
From above, it can be concluded that availability of early detection and warning is relatively higher in the U.S.A. in general than in Japan. However, for the age groups, 65 and older and 5 and under in both the U.S.A. and Japan, further fire protection measures such as a residential sprinkler must be considered to reduce these victims, because older adults and young children in both countries seem to have limitations that would keep them from responding to smoke detectors.

\section{CONCLUDING REMARKS}

In terms of fire death rates, the U.S.A. still has much higher rates than the U.K. and Japan in almost every age group and especially in age 4 and under, but Japan has the highest rate in age 80 and older, although Japan's overall average rate is the lowest. It is found that older or handicapped victims tended to be closer to the fire origin in Japan, which suggests that further consideration besides early detection and warning is needed to reduce those victims. Interestingly, there are considerable common patterns between the U.K. and Japan in terms of fire risk, even though Japan seems to be quite different from the U.K. in housing conditions and life style. To confirm and extend the above results, further study is earnestly recommended through international collaboration such as exchange of information as well as common effort toward uniformity of categorization of fire data.

\section{ACKNOWLEDGMENT}

The author is grateful to Dr. John Hall, Fire Research \& Analysis, the NFPA in the U.S.A. and Ms. Gillian Goddard, Fire Statistics Section, the Home Office in the U.K. for their help in providing the sources for fire statistics on each country.

\section{REFERENCES}

1. The Home Office, the United Kingdom, Fire Statistics - United Kingdom, 1989, 1990.

2. Fire Defense Agency, Japan, White Book on Fire Service in Japan, $1975-1990$.

3. Hall, J., "The U.S. Fire Problem Overview Report through 1990 - Leading Causes and Other Patterns and Trends", Publication of Fire Analysis and Research Division, National Fire Protection Association, February 1992.

4. Karter, M., "Patterns of Fire Casualties in Home Fires by Age and Sex, 1985-89", Publication of Fire Analysis and Research Division, National Fire Protection Association, February 1992.

5. Fahy, R., "Fatal Fires and Unsupervised Children", Fire Journal, pp. 19-24, January February, 1986.

6. Hall, J., "Fire in the U.S.A. and the United Kingdom - International Fire Comparison Report \#4", Publication of Fire Analysis and Research Division, National Fire Protection Association, August 1991. 
